\title{
A Regular, Wide-QRS Complex Tachycardia: What is the Tachycardia Mechanism?
}

\author{
FRED MORADY, M.D.

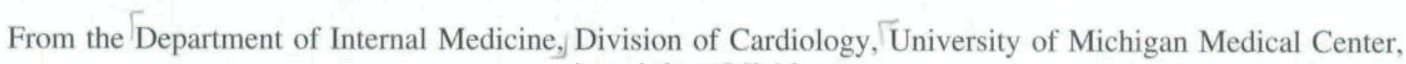 \\ Ann Arbor. Michigan
}

\section{Case Presentation}

A 45-year-old woman underwent an electrophysiology procedure because of a 20-year history of recurrent episodes of paroxysmal tachycardia. The baseline sinus cycle length, atrial-His, and His-ventricular intervals were 700, 60 , and $45 \mathrm{msec}$, respectively, and the QRS duration was $80 \mathrm{msec}$. Ventricular pacing at a cycle length of $300 \mathrm{msec}$ induced a tachycardia that had a cycle length of $320 \mathrm{msec}$ and a QRS duration of $120 \mathrm{msec}$, with a right bundle branch block configuration (Fig. 1). The tachycardia was terminated by ventricular pacing at cycle lengths shorter than $290 \mathrm{msec}$. Atrial pacing at a cycle length of $320 \mathrm{msec}$ was performed in the setting of sinus rhythm (Fig. 2).

What is the mechanism of this tachycardia?

\section{Commentary}

The His-ventricular interval during this tachycardia is $45 \mathrm{msec}$, which is the same as during sinus rhythm. This, along with the fact that atrial pacing results in the same right bundle branch block QRS configuration as during the tachycardia, rules out the possibility of ventricular tachy-

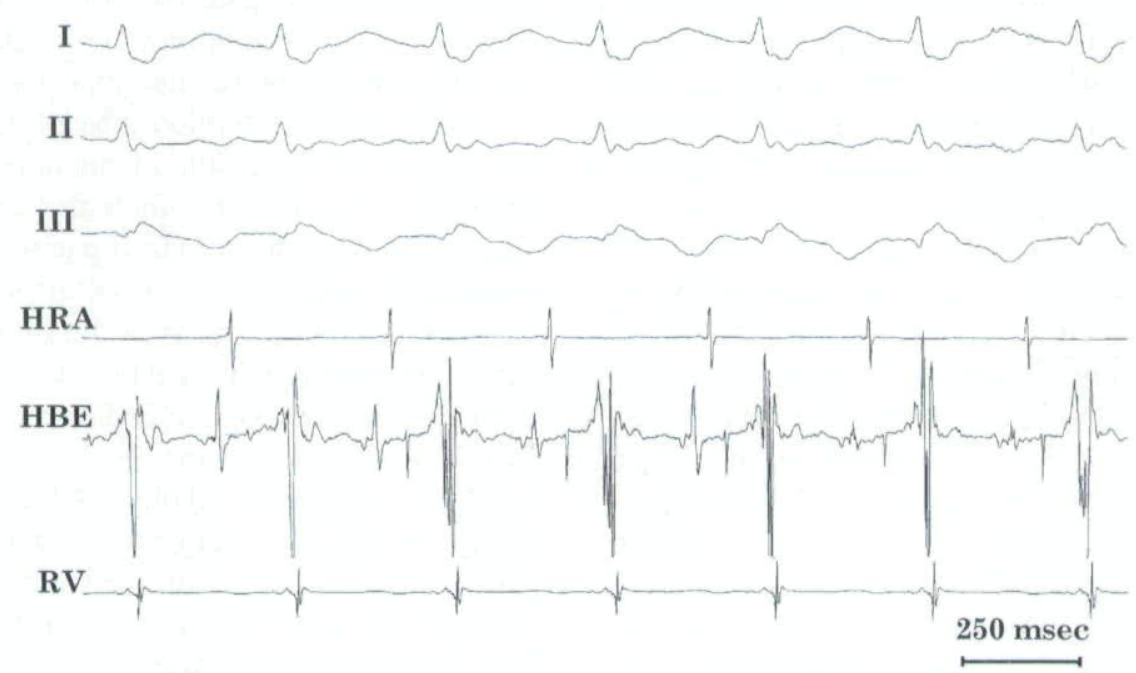

Figure 1. A wide-QRS complex tachycardia that has a cycle length of $320 \mathrm{msec}$. Shown are leads I, II, and III, the high right atrial electrogram (HRA), His-bundle electrogram (HBE), and a right ventricular electrogram (RV).

J Cardiovasc Electrophysiol, Vol. 10, pp. 623-624, April 1999.

Address for correspondence: Fred Morady, M.D., B1-F245, University of Michigan Medical Center, 1500 East Medical Center
Drive, Ann Arbor, MI 48109-0022. Fax: 734-936-7026.

Manuscript received 21 August 1998; Accepted 24 August 1998. 


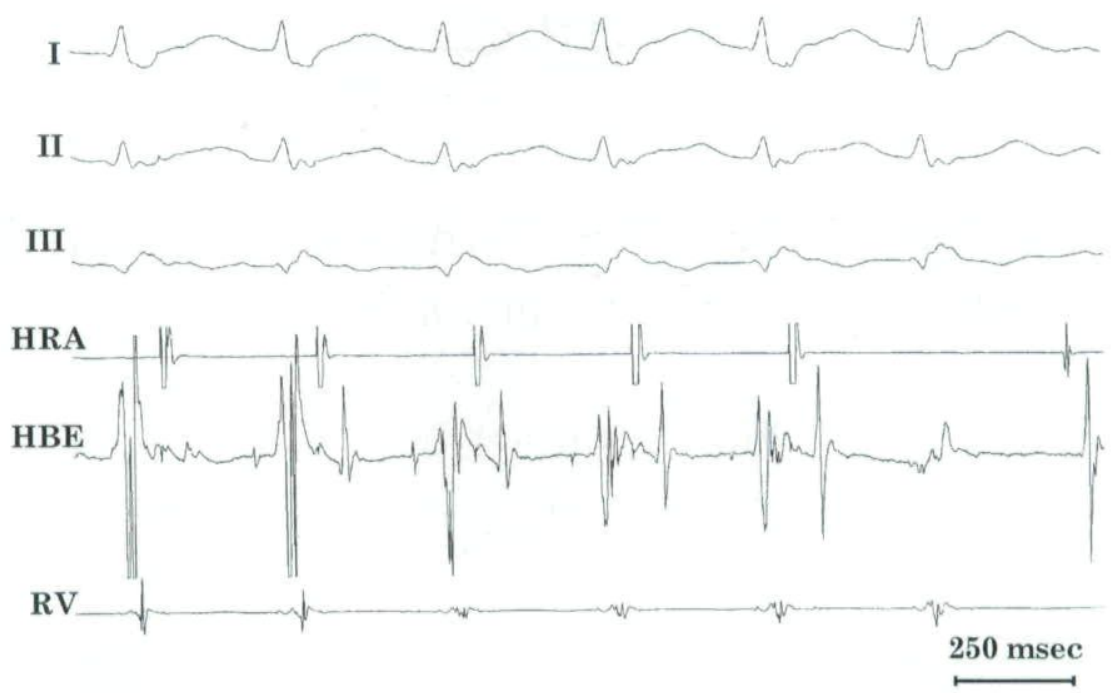

Figure 2. Atrial pacing at a cycle length of $320 \mathrm{msec}$, in the setting of sinus rhythm. Abbreviations same as in Figure 1.

cardia and indicates that this is a supraventricular tachycardia with a rate-related bundle branch block.

The RP interval in this tachycardia is longer than the PR interval, and the three most common causes of this type of paroxysmal supraventricular tachycardia are atypical atrioventricular (AV) nodal reentrant tachycardia, orthodromic reciprocating tachycardia, and atrial tachycardia. The intracardiac electrograms in Figure 1 do not provide any information helpful in distinguishing these possibilities. However, the response to atrial pacing at the same cycle length as the tachycardia (Fig. 2) does provide useful information. The atrial-His interval during the tachycardia is $70 \mathrm{msec}$, compared to $150 \mathrm{msec}$ during atrial pacing. This large discrepancy in atrial-His intervals between tachycardia and atrial pacing at the same cycle length is characteristic of atypical AV nodal reentrant tachycardia. ${ }^{1}$ In orthodromic reciprocating tachycardia or atrial tachycardia, there may be a difference in atrial-His intervals between tachycardia and atrial pacing (attributable to penetration of the AV node from different directions), but this difference is rarely greater than 10 to $20 \mathrm{msec}$. An $80-\mathrm{msec}$ discrepancy in atrial-His intervals, as found in the present case, is specific for atypical AV nodal reentrant tachycardia. The difference in atrial-His intervals is attributable to conduction through the fast AV nodal pathway during atrial pacing and through the slow AV nodal pathway during tachycardia.

It may be argued that this type of discrepancy in atrial-His intervals is diagnostic of dual AV nodal pathways, but not atypical AV nodal reentrant tachycardia. However, in actual practice, when atrial tachycardia or orthodromic reciprocating tachycardia occurs in a patient with dual AV nodal pathways, the same pathway (either fast or slow) is utilized for conduction to the ventricle both during tachycardia and during atrial pacing at the same cycle length as the tachycardia.

It should be noted that there is one other type of tachycardia consistent with the findings in Figures 1 and 2, namely an automatic junctional tachycardia. During an automatic junctional tachycardia, 1:1 retrograde conduction through the AV node to the atrium could result in an apparent atrial-His interval that is shorter than the actual atrial-His interval present during atrial pacing. An automatic junctional tachycardia can be differentiated from AV nodal reentrant tachycardia by the response to atrial and ventricular pacing; AV nodal reentrant tachycardia is entrainable, whereas automatic junctional tachycardia is not.

Consistent with atypical AV nodal reentrant tachycardia, the tachycardia was successfully eliminated (along with retrograde conduction through the AV node), by radiofrequency ablation of the slow pathway.

\section{Reference}

1. Man KC, Niebauer M, Daoud E, et al: Comparison of atrial-His intervals during tachycardia and atrial pacing in patients with long RP tachycardia. J Cardiovasc Electrophysiol 1995;6:700-710. 
This document is a scanned copy of a printed document. No warranty is given about the accuracy of the copy. Users should refer to the original published version of the material. 